\title{
BMJ Open Are service and patient indicators different in the presence or absence of nurse practitioners? The EDPRAC cohort study of Australian emergency departments
}

\author{
Sandy Middleton, ${ }^{\oplus 1}$ Glenn Gardner, ${ }^{2}$ Anne Gardner, ${ }^{3}$ Julie Considine, ${ }^{4}$ \\ Gerard Fitzgerald, ${ }^{3}$ Luke Christofis, ${ }^{5}$ Anna Doubrovsky, ${ }^{2}$ Phillip Della, ${ }^{6}$ \\ Oyebola Fasugba, ${ }^{1}$ Catherine D'Este ${ }^{7,8}$
}

To cite: Middleton S, Gardner G, Gardner A, et al. Are service and patient indicators different in the presence or absence of nurse practitioners? The EDPRAC cohort study of Australian emergency departments. BMJ Open 2019;9:e024529. doi:10.1136/ bmjopen-2018-024529

- Prepublication history and additional material for this paper are available online. To view these files, please visit the journal online (http://dx.doi org/10.1136/bmjopen-2018024529).

Received 06 June 2018 Revised 02 April 2019 Accepted 04 July 2019

Check for updates

(c) Author(s) (or their employer(s)) 2019. Re-use permitted under CC BY-NC. No commercial re-use. See rights and permissions. Published by BMJ.

For numbered affiliations see end of article.

Correspondence to Professor Sandy Middleton; Sandy.Middleton@acu.edu.au

\section{ABSTRACT}

Objectives To evaluate the impact of nurse practitioner (NP) service in Australian public hospital emergency departments (EDs) on service and patient safety and quality indicators.

Design and setting Cohort study comprising ED presentations (July 2013-June 2014) for a random sample of hospitals, stratified by state/territory and metropolitan versus non-metropolitan location; and a retrospective medical record audit of ED re-presentations.

Methods Service indicator data (patient waiting times for Australasian Triage Scale categories 2, 3, 4 and 5; number of patients who did not-wait; length of ED stay for non-admitted patients) were compared between EDs with and without NPs using logistic regression and Cox proportional hazards regression, adjusting for hospital and patient characteristics and correlation of outcomes within hospitals. Safety and quality indicator data (rates of ED unplanned re-presentations) for a random subset of re-presentations were compared using Poisson regression.

Results 0 f 66 EDs, 55 (83\%) provided service indicator data on 2463543 ED patient episodes while 58 (88\%) provided safety and quality indicator data on 2853 ED re-presentations. EDs with NPs had significantly $(p<0.001)$ higher rates of waiting times compared with EDs without NPs. Patients presenting to EDs with NPs spent $13 \mathrm{~min}(8 \%)$ longer in ED compared with EDs without NPs (median, (first quartile-third quartile): 156 (93-233) and 143 (84-217) for EDs with and without NPs, respectively). EDs with NPs had $1.8 \%$ more patients who did not wait, but similar re-presentations rates as EDs with NPs.

Conclusions EDs with NPs had statistically significantly lower performance for service indicators. However, these findings should be treated with caution. NPs are relatively new in the ED workforce and low NP numbers, staffing patterns and still-evolving roles may limit their impact on service indicators. Further research is needed to explain the dichotomy between the benefits of NPs demonstrated in individual clinical outcomes research and these macro system-wide observations.
Strengths and limitations of this study

- To our knowledge, this is the first study internationally to compare at a systems level the differences in service and patient safety and quality indicators for emergency departments (EDs) with nurse practitioner (NPS) on the service team and EDs without NPS.

- This large national study included data for over two million ED patient presentations collected prospectively.

- The study investigated NP service by collecting data at the system rather than individual NP level; this is a study strength and a departure from the prevailing approach to NP research.

- This was an observation study, thus there was no random allocation of NP implementation.

- Data custodians from two jurisdictions were unable to provide service indicator data, and one of these jurisdictions did not provide safety and quality data.

\section{INTRODUCTION}

Emergency departments (ED) are the safety net of healthcare providing care to patients with life-threatening conditions through to non-urgent clinical conditions regardless of financial status. ${ }^{1}$ Worldwide, EDs are overcrowded because of increased health service demand, access block ${ }^{2}$ and increasing presentations with complex care needs. ${ }^{3}{ }^{4}$ This overcrowding results in increased patient suffering, increased waiting times, patients leaving without being seen, decreased quality of services and undesirable impact on ED staff ${ }^{56}$ and adverse patient outcomes. ${ }^{57}$

In response to the risk to patient safety and quality, health service managers have implemented workforce reforms. The use of nurse practitioners (NPs) in the ED has been one 
of the most frequently adopted workforce solution internationally. ${ }^{8}$ The NP role originated in the USA to meet demand for primary care services. ${ }^{9} 10$ The UK has seen an increase in NPs in the ED, both in numbers and scope of practice. ${ }^{11}$ In Australia, emergency NP service is a relatively new nursing model of care, and previous work from our team demonstrated that EDs employ the highest proportion of Australian NPs. ${ }^{12}$ The ED NP role was initially developed to address the management of patients presenting to EDs with minor illness or injury. ${ }^{14}$ However, the dynamic and flexible nature of the NP role ${ }^{14}$ extends to complex and in-depth management of patients. There are differences between NPs in the UK and Australia, notably the absence of formal regulation of the UK NP title, ${ }^{11}$ making international comparisons of the role difficult. Despite the rapid uptake of the NP role, research evaluating this service model around patient safety and quality outcomes is lacking.

In addition to the use of NPs to combat ED overcrowding and increasing ED attendances for low complexity problems, ${ }^{34}$ fast track units have been created in many countries. ${ }^{915}$ These functionally distinct units within EDs allow low-acuity patients to be streamlined from triage and seen separately. ${ }^{16}$ Research from both Australia and UK show that NPs are a suitable staffing choice for fast track areas. ${ }^{16-18}$

Research to date has focused on service and clinical outcomes of individual NP roles without acknowledging that the strategy of implementing the NP role in ED is an innovation aimed at system improvement. ${ }^{19}$ A new evaluation approach is needed, acknowledging that addition of NPs (both emergency specialist NPs and NPs from other specialties) to the ED clinical team is complex, with service consequences that extend beyond the individual clinician. Implementation of the NP role in EDs has met with challenges. ${ }^{9}{ }^{20}$ Unclear expectations including blurring of NP responsibilities and role boundaries with other nursing and medical staff often leads to confusion about the role. ${ }^{20}$ EDs in Australia and internationally now employ NPs as part of their health service delivery team, ${ }^{11} 21$ therefore high-quality multi-site research using appropriate inquiry approaches to comprehensively evaluate the effectiveness of NP service in EDs is warranted. ${ }^{22}$

This research aimed to compare service and patient safety and quality indicators for EDs with NPs on the service team and EDs without NPs. For the first time in Australia, research has examined the direct and/or systems impact of NP service on ED outcomes.

\section{METHOD}

This study involved a cohort of ED patients and a nested retrospective medical record audit to compare service and quality indicators in Australian public hospital EDs with and without NPs. Data from three sources were used: (1) a national survey on hospital and ED characteristics (previously reported), ${ }^{21}$ (2) ED administrative data measuring service indicators of the ED episodes and (3) data abstraction from patient medical records to assess rates of unplanned patient re-presentation. The study was undertaken from July 2013 to June 2014.

\section{Hospital eligibility and recruitment}

All 155 Australian public hospitals providing 24-hour medical and nursing staff emergency services and reporting ED data to the Australian Institute of Health and Welfare identified from the MyHospitals website (https://www.myhospitals.gov.au) as in June 2012 completed a national telephone survey on ED organisation, staffing and service models. ${ }^{21} \mathrm{~A}$ random sample of 66 of the 155 hospitals who participated in the survey, stratified by state/territory (geographical/jurisdictional units) and location (metropolitan/non-metropolitan) provided data on ED presentations. Data custodians from each hospital or health department were approached for access to administrative data.

\section{Patient eligibility}

Study participants were all patients in Australasian Triage Scale (ATS) categories 2, 3, 4 and 5 (The ATS is a rating scale ensuring that patients are seen according to their clinical urgency. The maximum wait time indicator for each category is: 1: immediate; 2: $10 \mathrm{~min} ; 3: 30 \mathrm{~min}$; 4: 1 hour; 5: 2 hours. $)^{23}$ who presented to participating EDs during the study period. Category 1 patients were excluded because, in addition to small numbers, NPs rarely initiate or manage treatment for this cohort in hospital EDs that met the study inclusion criteria.

\section{Data collection}

The hospital survey ${ }^{21}$ collected data on a range of characteristics related to hospitals (location: state/territory; type: major referral, urban district, regional and ED size: categorised as small ( $<30000$ episodes per year), medium (30000-60 000 episodes), large (>60000 episodes); ED services (fast track, rapid assessment team, short stay/ sub-acute care, aged care liaison as described previously ${ }^{21}$; and nursing (nurse educator, clinical nurse consultant, enrolled nurse), medical (staff specialists, registrars, residents/interns) and allied health (access to radiology) workforce factors. These variables were considered to be important ED features likely to be associated with ED management and clinical care. EDs were categorised based on presence or absence of NPs on the ED service team including NPs who serviced a specific population such as aged care or mental health. ${ }^{21}$ Data on NP characteristics were limited to those relating to the NP service model, other variables of education and experience are standardised across Australia. In order to gain authorisation as a NP in Australia the nurse must demonstrate to the registering authority a minimum 3 years' experience as a senior clinician and completion of a board-accredited NP masters' degree. ${ }^{24}$

Service indicator data were collected prospectively from routinely collected computerised hospital administrative data over a 12-month period, from July 2013 to 
June 2014, to capture the effects of seasonal variation on demand for ED services. Patient-level data obtained were: medical record number, date of birth, sex, date and time of presentation, date and time seen by an ED clinician, date and time the patient left ED, whether or not the patient was seen by a clinician and whether or not they completed their treatment, presenting condition, ATS category, mode of transport to ED and final diagnosis as determined by national coding processes. ${ }^{25}$ Three service indicators were measured from administrative data: (1) patient waiting times for ATS categories 2, 3, 4 and 5; (2) number of patients who 'did not wait' (DNW), defined as patients who did not wait to be seen by clinical staff (doctor or nurse) or patients who had been seen but left before completion of treatment; and (3) overall length of stay in ED for patients who were not admitted, transferred or left without being seen or before completion of treatment. Length of time in the department for admitted patients is influenced by factors beyond the ED such as the availability of hospital beds, thus non-admitted patients are a more appropriate population in which to measure length of ED stay.

The safety and quality indicator measured in this study was the rate of unplanned ED re-presentations within 48 hours. This variable identified accuracy and appropriateness of clinical care and data were readily available. Patients who re-presented to the same ED within 48 hours of their initial presentation were identified over a 3-month period from 1 July to 30 September 2013 from computerised ED data systems. A random sample of 50 of these re-presenting patients were selected for each ED using random number generating software and a retrospective medical record audit undertaken by trained research nurses. Notes for the initial presentation and reasons for re-presentations were reviewed and the re-presentation was classified as unplanned if the second visit was for an unrelated cause, or there was no indication that patient had been asked to reattend in the initial visit; re-presentations where the patient had been requested to return for follow-up, or if their condition worsened or further developed were not classified as unplanned.

\section{Sample size}

Calculation of sample size was informed by national data including published and unpublished local data and based on $80 \%$ power and a $5 \%$ significance level. An intraclass correlation of 0.02 was used to estimate the design effect due to correlation of measures within hospitals. The outcome 'proportion of patients seen on time' required the largest sample size and was therefore used to estimate the sample size required. The total sample size required to detect a $5 \%$ difference in this outcome (from both NP and non-NP EDs combined) for ATS 3 and ATS 4 triage categories was estimated to be 744916 and 939104 patients, respectively. Assuming a 1:1 ratio of NP to non-NP EDs, the number of EDs needed was 56 (based on the larger of these two sample size estimates).

\section{Data analysis}

Data were analysed using Stata V.13 and 14. Data checks and exploratory data analyses were undertaken to check for out of range or unusual/illogical values. For service indicator outcomes, univariable associations were initially examined using two-way tables and univariable logistic regression for the DNW outcome and univariate Cox proportional hazards regression for patient waiting time, and length of stay. Multiple regression models were generated including core covariates of interest: presence or absence of NP; hospital location; hospital type; ED size; patient age category, patient sex and ATS category (2, 3, 4 or 5, where ATS-specific models were not generated). Due to possible multi-collinearity, correlations among arrival mode and other hospital-level variables, nursing workforce variables, medical workforce variables and access to radiology were assessed and relevant (non-correlated) variables were then added individually, and retained in the model if the $p$ value for the Wald test assessing their association with the outcome was $\leq 0.1$. As waiting times for ED patients vary according to their triage category, separate models were generated by triage category for this outcome.

Given the potential for NPs to have greater impact in less urgent presentations, models were also generated with an interaction term for NP by ATS category, however as none of these interactions were statistically significant only the main effects models are reported. Analyses adjusted for correlation of observations within hospitals using the Huber-White (sandwich) (cluster) variance estimate. Sensitivity analysis was undertaken on the DNW outcome for the subgroup of patients who did not wait to be seen by clinical staff (ie, defining patients who had been seen but left before completion of treatment as having waited).

The safety and quality indicator outcome (rates of unplanned re-presentations within 48 hours) was considered at the ED level. The overall rate of re-presentation was calculated as number of re-presentations divided by the total number of ED presentations. The proportion of unplanned re-presentations was based on the subgroup of re-presenting patients whose records were reviewed and calculated as number of unplanned re-presentations divided by the sum of number of planned and unplanned re-presentations. The overall rate of unplanned re-presentations was calculated as overall rate of re-presentation multiplied by proportion of unplanned re-presentations.

In assessing the service indicator outcomes, a significance level of $p<0.01$ was used to take some account of the large number of observations (ED presentations), while a significance level of $\mathrm{p}<0.05$ was used for the safety and quality indicator outcome, which was based on a subsample of ED presentations.

\section{Patient and Public involvement}

Patients were not involved in the design and conduct of this study, however there was extensive involvement of industry partners in this study. This team of health service leaders 
(see acknowledgements) collaborated with the study team in setting project goals, confirming feasibility of study design and establishing project deliverables. When the project was in progress the industry partners formed joint membership of the project advisory committee, received progress reports and provided feedback. On completion of the project, the study findings were discussed with industry partners to inform health service policy and workforce planning in emergency services across Australia.

\section{RESULTS}

Of the 155 Australian public hospital EDs that met the eligibility criteria, $135(87 \%)$ provided survey data; while 61 of the 66 asked to provide ED data consented and had ethical approval to participate in the study. Of the 66 hospitals, 55 (83\%) provided service indicator data on 2463536 ED patient episodes from July 2013 to June 2014 while 58 $(88 \%)$ provided safety and quality indicator data on 2853 ED patient re-presentations from July to September 2013. Of the 2900 re-presentations selected for this component of the study, 47 patient records could not be located.

Service indicator data could not be obtained from Western Australia and Northern Territory because data custodians were unable to provide access to data despite the study obtaining Human Research Ethics Committee (HREC) approval. However, the Western Australian Department of Health data custodian did provide safety and quality indicator data on re-presentations which were included in analyses.

\section{Demographic characteristics of EDs and emergency episodes}

Characteristics of the 61 Australian EDs recruited to participate in the study are presented in table 1 . Approximately a third of EDs were located in New South Wales, half were from regional or rural locations with $25 \%$ described as urban district and $27 \%$ as major referral metropolitan EDs.

Just over half of EDs $(n=33 ; 55 \%)$ employed NPs, of which $15(45 \%)$ employed fewer than two NP fulltime equivalent (FTE) and $18(55 \%)$ employed $\geq 2 \mathrm{NP}$ FTE. Thirteen EDs employed NPs restricted to treating patients in triage categories urgent to non-urgent (ATS categories 3-5), while in the remaining EDs, NPs also covered emergency (ATS category 2) patients. All EDs employed registered nurses, $38 \%$ also employed clinical nurse consultants and $73 \%$ employed nurse educators.

There were similar numbers of male and female patients presenting to ED during the study period. Patient age was bimodal with peaks for infants aged between 0 and 4 years and for adults from 20 to 40 years. School age children (5-19 years) were under-represented compared with adults. The majority of ED episodes were classified as urgent (ATS category 3: 38\%) or semi-urgent (ATS category $4: 41 \%)$. Over $30 \%$ ( $n=763944)$ of presentations were for patients diagnosed with infectious diseases or injury (table 2).

\section{Patient waiting times}

Factors associated with waiting times of patients in EDs for each ATS category are shown in table 3 (also see online
Table 1 Characteristics of hospital emergency departments $(n=61)^{*}$

\begin{tabular}{|c|c|}
\hline Characteristic & n (\%) \\
\hline \multicolumn{2}{|l|}{ State strata } \\
\hline NSW & $22(36)$ \\
\hline VIC & $15(25)$ \\
\hline QLD & $13(21)$ \\
\hline WA & $6(10)$ \\
\hline SA/TAS/ACT & $5(8)$ \\
\hline \multicolumn{2}{|l|}{ ACEM classification } \\
\hline Major referral & $16(27)$ \\
\hline Urban district & $15(25)$ \\
\hline Major regional/rural & $29(48)$ \\
\hline \multicolumn{2}{|c|}{ ED size (number of presentations) } \\
\hline$<35000$ & $18(33)$ \\
\hline $35000-<50000$ & $18(33)$ \\
\hline $50000+$ & $19(35)$ \\
\hline Nurse practitioner in ED & $33(55)$ \\
\hline \multicolumn{2}{|l|}{ ED nurse practitioner FTE } \\
\hline No NP & $27(45)$ \\
\hline $\mathrm{NP}<2 \mathrm{FTE}$ & $15(25)$ \\
\hline $\mathrm{NP} \geq 2 \mathrm{FTE}$ & $18(30)$ \\
\hline \multicolumn{2}{|l|}{ Triage category services by NP } \\
\hline No NP & $27(48)$ \\
\hline NP 1-5 & $8(14)$ \\
\hline NP 2-5 & $8(14)$ \\
\hline NP 3-5/4-5 & $13(23)$ \\
\hline \multicolumn{2}{|l|}{ Other clinical positions } \\
\hline Nurse educator & $44(73)$ \\
\hline Clinical nurse consultant & $23(38)$ \\
\hline Enrolled nurse & $49(82)$ \\
\hline Staff specialists & $50(83)$ \\
\hline Registrars & $46(77)$ \\
\hline Residents/interns & $51(85)$ \\
\hline \multicolumn{2}{|l|}{ Service operation models } \\
\hline Access to radiology & $39(65)$ \\
\hline Fast track & $45(75)$ \\
\hline Rapid assessment team & $25(42)$ \\
\hline Short stay/sub-acute care & $40(67)$ \\
\hline Aged care liaison & $40(67)$ \\
\hline
\end{tabular}

Numbers may not add to total sample size due to missing data. *Only 55 hospitals provided service indicator data.

ACEM, Australian College for Emergency Medicine; ACT, Australian Capital Territory; ED, emergency department; FTE, full-time equivalent; NP, nurse practitioner; NSW, New South Wales; QLD, Queensland; SA, South Australia; TAS, Tasmania; VIC, Victoria; WA, Western Australia.

supplementary file). EDs with NPs had significantly higher median waiting times $(\mathrm{p}<0.001)$ compared with EDs without NPs for all ATS categories with the exception of ATS category 5 . Median waiting times were longer in Queensland for all ATS categories (from 8 to $47 \mathrm{~min}$ ) 
Table 2 Characteristics of emergency department patient presentations ( $n=2463543$ )

\begin{tabular}{|c|c|}
\hline Characteristic & n (\%) \\
\hline \multicolumn{2}{|l|}{ Sex } \\
\hline Male & $1236316(50)$ \\
\hline Female & $1227220(50)$ \\
\hline \multicolumn{2}{|l|}{ Age group } \\
\hline $0-4$ & $261511(11)$ \\
\hline $5-9$ & $114538(5)$ \\
\hline $10-14$ & $108599(4)$ \\
\hline $15-19$ & $168420(7)$ \\
\hline 20-29 & $377320(15)$ \\
\hline 30-39 & $307969(13)$ \\
\hline $40-49$ & $266846(11)$ \\
\hline $50-59$ & $237614(10)$ \\
\hline $60-69$ & $215492(9)$ \\
\hline $70-79$ & $192395(8)$ \\
\hline $80+$ & $212832(9)$ \\
\hline \multicolumn{2}{|l|}{ Triage category } \\
\hline Emergency (2) & $306399(12)$ \\
\hline Urgent (3) & $936106(38)$ \\
\hline Semi-urgent (4) & $1017746(41)$ \\
\hline Non-urgent (5) & $203285(8)$ \\
\hline \multicolumn{2}{|l|}{ Final primary diagnosis } \\
\hline Infectious/injury/external & $763944(31)$ \\
\hline Circulatory/respiratory & $304380(12)$ \\
\hline Skin/subcutaneous/musculoskeletal & $189591(8)$ \\
\hline Endocrine/nutrition/metabolism & $164962(7)$ \\
\hline Health status/health services & $144820(6)$ \\
\hline Genitourinary & $143103(6)$ \\
\hline Mental/behavioural & $88634(4)$ \\
\hline Eye/adnexa/ear/mastoid & $51444(2)$ \\
\hline $\begin{array}{l}\text { Pregnancy/childbirth/perinatal/ } \\
\text { congenital }\end{array}$ & $46287(2)$ \\
\hline Nervous system & $39727(2)$ \\
\hline Neoplasms/blood & $23262(1)$ \\
\hline Other clinical/laboratory/unknown & $503382(20)$ \\
\hline
\end{tabular}

compared with other jurisdictions. For ATS categories 3 and 4, male patients were significantly more likely to be seen before female patients, however the difference in median waiting time was small at $1 \mathrm{~min}$. While EDs with fast track had longer median waiting times compared with those without fast track, the difference was significant for ATS category 3 only $(p<0.01)$. Results for Cox proportional hazards models for each ATS category are provided in table 3 .

Patients who did not wait

A total of 63366 (2.6\%) patients did not wait to be seen. Patients in EDs employing NPs had higher odds of not waiting (OR: $1.895 \%$ CI 1.4 to 2.2 ; $\mathrm{p}<0.001$ ) compared with EDs without NPs (table 4). Female patients had higher odds of waiting compared with males. The odds of not waiting increased with increasing ATS category (decreasing level of urgency). For additional results for other covariates (hospital location, ED size and diagnostic group) see online supplementary file.

\section{Length of stay in ED for non-admitted patients}

Of the 1470304 patients not admitted following their ED presentation, 826024 attending EDs with NPs spent a median of $156 \mathrm{~min}$ in ED compared with a median length of stay of $143 \mathrm{~min}$ for 644280 patients from EDs without NPs (HR 0.87, 95\% CI 0.81 to $0.95, \mathrm{p}=0.001$ ). Patients in Queensland spent the shortest time in the ED. Male patients were significantly more likely to be discharged sooner than female patients (HR 0.94, 95\% CI 0.94 to $0.95, \mathrm{p}<0.001$ ) (table 5 ). Length of stay decreased with decreasing level of urgency (higher ATS category). Increasing age was associated with longer time in the ED for discharged patients with children spending a median of approximately 2 hours in the ED increasing in a linear fashion to patients aged over 80 years who spent over 3.5 hours in ED.

Model also adjusted for hospital type and diagnostic group; an HR of $<1$ indicates that patients in this group are less likely to be discharged, compared with the reference group.

\section{Rates of unplanned re-presentation}

EDs with NPs did not differ in rates of unplanned re-presentations compared with EDs without NPs. Significant reductions in the rates of unplanned re-presentations were seen in EDs with fast track (IRR 0.74, 95\% CI 0.60 to $0.92, \mathrm{p}=0.006$ ) and those with aged care liaison models (IRR $0.72,95 \%$ CI 0.54 to $0.96, \mathrm{p}=0.023$ ), with a marginally non-significant increase in re-presentations associated with the presence of a Nurse Educator (IRR 1.22, 95\% CI 0.99 to $1.50, \mathrm{p}=0.060$ ) (see online supplementary file).

\section{DISCUSSION}

Notably, this study is novel in Australia and globally in its systems-level comparison of differences in both service and patient safety and quality indicators for EDs with and without NPs on the clinical team. Our results showed that EDs with NPs had lower performance for three routinely measured ED service indicators. There were longer waiting times in EDs with NPs for patients allocated ATS categories 2, 3 and 4. While this difference is statistically significant, the clinical significance is not established, given the small magnitude of difference. The difference in waiting times was not significant for ATS category 5; these patients are more likely to be seen by an $\mathrm{NP}^{21}$ so would be more likely to have shorter waiting times. EDs with fast track had longer patient waiting times for ATS category 3 and EDs with NPs had higher odds of patients 


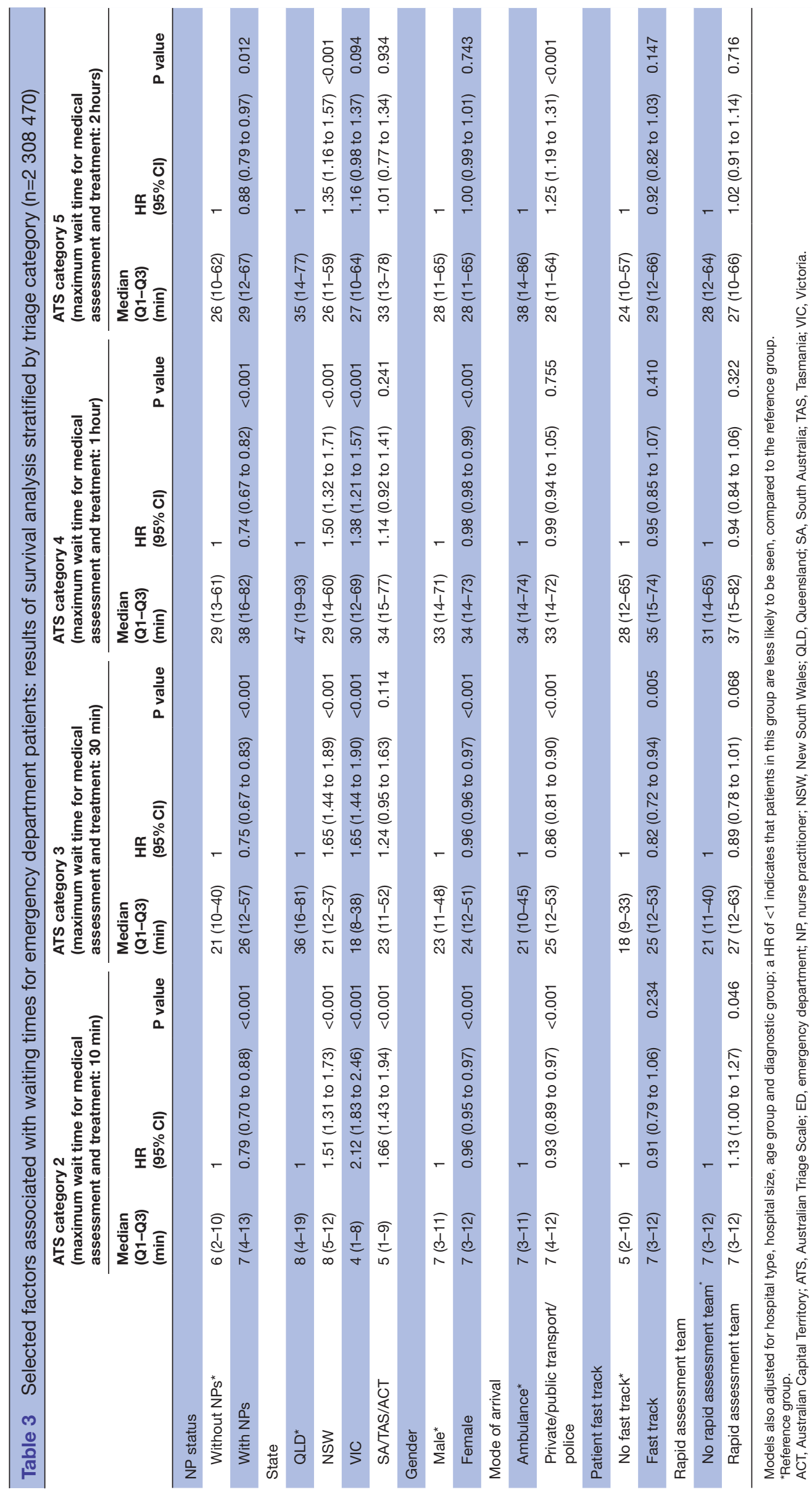


Table 4 Factors associated with not waiting for completion of treatment $(n=2446935)$

$\begin{array}{llll}\text { n } & \% & \text { OR }(95 \% \mathrm{Cl}) & \text { P value }^{*}\end{array}$

\begin{tabular}{|c|c|c|c|c|}
\hline \multicolumn{5}{|l|}{ NP status } \\
\hline Without NPs† & 47289 & 4.5 & 1 & \\
\hline With NPs & 87638 & 6.3 & 1.78 (1.42 to 2.23$)$ & $<0.001$ \\
\hline \multicolumn{5}{|l|}{ Hospital type } \\
\hline Major referral† & 45477 & 5.0 & 1 & \\
\hline Urban district & 35454 & 6.7 & 1.55 (1.11 to 2.16$)$ & 0.010 \\
\hline Major regional/rural & 53996 & 5.4 & $0.9(0.60$ to 1.37$)$ & 0.639 \\
\hline \multicolumn{5}{|l|}{ Rapid assessment team } \\
\hline No rapid assessment team $†$ & 71554 & 5.4 & 1 & \\
\hline Rapid assessment team & 63373 & 5.7 & 1.26 (1.00 to 1.58$)$ & 0.049 \\
\hline \multicolumn{5}{|l|}{ Radiology } \\
\hline No radiology $†$ & 40315 & 4.9 & 1 & \\
\hline Radiology & 94612 & 5.8 & 1.33 (0.99 to 1.78$)$ & 0.060 \\
\hline \multicolumn{5}{|l|}{ Age group } \\
\hline $0-4$ & 17204 & 6.6 & 1 & \\
\hline $5-9$ & 6583 & 5.8 & 0.82 (0.78 to 0.86$)$ & $<0.001$ \\
\hline $10-14$ & 4818 & 4.5 & 0.63 (0.58 to 0.68$)$ & $<0.001$ \\
\hline $15-19$ & 12040 & 7.2 & 0.82 (0.72 to 0.94$)$ & 0.004 \\
\hline $20-29$ & 30277 & 8.1 & 0.86 (0.73 to 1.01$)$ & 0.058 \\
\hline $30-39$ & 22279 & 7.3 & 0.78 (0.66 to 0.94$)$ & 0.007 \\
\hline $40-49$ & 16844 & 6.4 & 0.74 (0.62 to 0.89$)$ & 0.001 \\
\hline $50-59$ & 11874 & 5.0 & 0.61 (0.51 to 0.73 ) & $<0.001$ \\
\hline $60-69$ & 6871 & 3.2 & 0.39 (0.33 to 0.46$)$ & $<0.001$ \\
\hline $70-79$ & 3890 & 2.0 & 0.25 (0.22 to 0.29$)$ & $<0.001$ \\
\hline $80+$ & 2247 & 1.1 & 0.13 (0.11 to 0.16$)$ & $<0.001$ \\
\hline \multicolumn{5}{|l|}{ Sex } \\
\hline Male† & 68175 & 5.6 & 1 & \\
\hline Female & 66752 & 5.5 & 0.79 (0.75 to 0.85$)$ & $<0.001$ \\
\hline \multicolumn{5}{|l|}{ Triage category } \\
\hline Emergency (2)† & 4284 & 1.4 & 1 & \\
\hline Urgent (3) & 34178 & 3.7 & 2.32 (1.97 to 2.74 ) & $<0.001$ \\
\hline Semi-urgent (4) & 75182 & 7.4 & 5.43 (4.40 to 6.71$)$ & $<0.001$ \\
\hline Non-urgent (5) & 21283 & 10.6 & 4.76 (3.08 to 7.37$)$ & $<0.001$ \\
\hline
\end{tabular}

Model also adjusted for state, hospital size and diagnostic group.

${ }^{*} \mathrm{P}$ values from Wald test.

†Reference group.

NP, nurse practitioner.

not waiting for treatment completion compared with EDs without NPs.

The trend, nationally and internationally, of a high uptake of NP service in the ED setting ${ }^{812} 13$ was supported and possibly influenced by early single site audit studies that reported NPs having a positive effect on service indicator data. ${ }^{26-28}$ EDs employed NPs in order to improve existing poor performance on service indicators. That these assumptions were not supported by the study findings can possibly be explained by the effect of reverse causation. That is, the existing poor performance on service indicators was the cause for EDs to employ NPs. In other words, poor performance was the cause, not the effect, of NP service.

Consistent with expectations, patients who arrived by ambulance had shorter waiting times for ATS categories 2 and 3 , and patients with more urgent triage categories had greater length of stay than less urgent categories. Elderly patients who are likely to have more comorbidities than the young, spent longer time than other groups in the ED. 
Open access

Table 5 Factors associated with length of stay in emergency department for discharged patients $(n=1470308)$

\begin{tabular}{|c|c|c|c|c|}
\hline & Median (min) & Q1-Q3 (min) & HR $(95 \% \mathrm{Cl})$ & P value* \\
\hline \multicolumn{5}{|l|}{ NP status } \\
\hline Without NPs $†$ & 143 & $84-217$ & 1 & \\
\hline With NPs & 156 & 93-233 & 0.87 (0.81 to 0.95$)$ & 0.001 \\
\hline \multicolumn{5}{|l|}{ State } \\
\hline QLD† & 135 & 80-206 & 1 & \\
\hline NSW & 159 & $93-233$ & 0.77 (0.69 to 0.86$)$ & $<0.001$ \\
\hline VIC & 150 & $90-228$ & 0.83 (0.74 to 0.93$)$ & 0.001 \\
\hline SA/TAS/ACT & 160 & $98-244$ & 0.8 (0.67 to 0.94$)$ & 0.007 \\
\hline \multicolumn{5}{|l|}{ Gender } \\
\hline Male† & 142 & $85-218$ & 1 & \\
\hline Female & 159 & $94-234$ & 0.94 (0.94 to 0.95$)$ & $<0.001$ \\
\hline \multicolumn{5}{|l|}{ Age group } \\
\hline $0-4 \dagger$ & 125 & $77-190$ & 1 & \\
\hline $5-9$ & 120 & $75-183$ & 0.97 (0.95 to 1.00$)$ & 0.086 \\
\hline $10-14$ & 123 & $78-187$ & 0.91 (0.87 to 0.96$)$ & $<0.001$ \\
\hline $15-19$ & 143 & $87-216$ & 0.78 (0.73 to 0.83$)$ & $<0.001$ \\
\hline $20-29$ & 149 & $89-223$ & 0.76 (0.71 to 0.82$)$ & $<0.001$ \\
\hline 30-39 & 154 & $91-229$ & 0.74 (0.68 to 0.79$)$ & $<0.001$ \\
\hline $40-49$ & 159 & $94-235$ & 0.70 (0.65 to 0.76$)$ & $<0.001$ \\
\hline $50-59$ & 164 & $97-240$ & 0.68 (0.63 to 0.73$)$ & $<0.001$ \\
\hline $60-69$ & 175 & $106-255$ & 0.65 (0.60 to 0.70$)$ & $<0.001$ \\
\hline $70-79$ & 193 & $118-283$ & 0.61 (0.56 to 0.66$)$ & $<0.001$ \\
\hline $80+$ & 222 & $143-328$ & 0.55 (0.51 to 0.60$)$ & $<0.001$ \\
\hline \multicolumn{5}{|l|}{ Triage category } \\
\hline Emergency (2)† & 191 & $130-276$ & 1 & \\
\hline Urgent (3) & 180 & $115-253$ & 1.06 (1.01 to 1.11$)$ & 0.012 \\
\hline Semi-urgent (4) & 138 & $83-214$ & 1.33 (1.25 to 1.41$)$ & $<0.001$ \\
\hline Non-urgent (5) & 95 & $52-157$ & 2.01 (1.88 to 2.16 ) & $<0.001$ \\
\hline \multicolumn{5}{|l|}{ ED size } \\
\hline$<35000 \dagger$ & 129 & $74-205$ & 1 & \\
\hline $35000-<50000$ & 137 & $82-212$ & $0.96(0.83$ to 1.11$)$ & 0.580 \\
\hline $50000+$ & 169 & $105-239$ & 0.7 (0.6 to 0.81$)$ & $<0.001$ \\
\hline \multicolumn{5}{|l|}{ Mode of arrival } \\
\hline Ambulance† & 208 & 138-306 & 1 & \\
\hline Private or public transport/police & 139 & 83-213 & $1.46(1.43$ to 1.50$)$ & $<0.001$ \\
\hline \multicolumn{5}{|l|}{ Liaison models aged } \\
\hline No liaison aged care $\dagger$ & 144 & $85-225$ & 1 & \\
\hline Liaison aged care & 152 & $91-228$ & 1.19 (1.06 to 1.34$)$ & 0.002 \\
\hline
\end{tabular}

Model also adjusted for hospital type and diagnostic group; an HR of $<1$ indicates that patients in this group are less likely to be discharged, compared with the reference group.

${ }^{*} P$ values from Wald test.

†Reference group.

ACT, Australian Capital Territory; NP, nurse practitioner; NSW, New South Wales; QLD, Queensland; SA, South Australia; TAS, Tasmania; VIC, Victoria.

Our safety and quality indicator of unplanned re-presentations showed no difference between EDs with and without NPs. However, when comparing re-presentations according to service models, EDs with fast track had a significantly lower rate, on average $25 \%$, of unplanned re-presentations. Our results are in part supported by 
previous research where individual NP care was the explanatory variable. A well-powered, Australian randomised controlled trial comparing emergency NP care with traditional care found no significant differences between groups for the same service indicators of waiting times, numbers of patients who did not wait and ED length of stay. ${ }^{29}$ However, results showed a significant difference in 'time to analgesia' in favour of NPs when compared with ED doctors. ${ }^{30}$ Similarly, Roche $e t a l^{19}$ found no significant difference between NP and traditional care on service indicators of waiting time and length of stay in rural EDs. For patients presenting to these rural EDs with undifferentiated chest pain however, NPs had a higher proportion of diagnostic accuracy of ECG interpretation, higher proportion of guideline adherence for high-risk patients and patients had 2.4 times lower odds of an unplanned re-presentation within 7 days when compared with the standard care model. These and other studies ${ }^{171820}$ indicate that the impact of NPs when compared with traditional care on service indicators is inconclusive and varies across settings. However, research on the influence of NP service on patients' clinical outcomes and quality of care is consistently shown to be equivalent or superior in comparison to traditional ED care.

The Emergency Department Nurse Practitioner (EDPRAC) national survey study showed that Australian EDs with NPs average two NP FTE nationwide, ${ }^{21}$ numbers insufficient to staff the 24 hours ED service time frame. These NP numbers and staffing patterns when compared with the scope of medical staffing (an average of $\sim 46$ medical staff FTE nationwide across 24 hours) are likely too small to have a clinically significant effect on service indicators in either direction. Furthermore, alternative influences related to EDs that employed NPs need to be taken into consideration, such as the level of health service planning and historical hospital performance on service indicators before including NPs in the team. Data on these variables were not collected. Within the timeframe of this study, the majority of NPs were in the early phases of their career $(\leq 5$ years post-endorsement NP experience) and therefore may not have worked to their full scope of practice.

Ultimately, our research raises questions about optimum deployment of the NP service model in EDs. While NPs may be a suitable choice for managing patients in ED fast track areas, the impact of their service may not have been appropriately captured by the routinely collected service indicators we measured which are multifactorial. Drivers other than ED staffing that impact on all service indicators include patient characteristics, non-urgent patient visits and hospital bed shortages. ${ }^{31}$ Evaluation of emergency NP service requires further consideration of which service indicators appropriately measure the safety and quality of patient care.

There are notable strengths to our study. This large exploration of ED service included data for over 2 million ED patient presentations. The study covered all jurisdictions in Australia (except Western Australia and Northern Territory) with data collected over a 12-month timeframe. Data from the EDPRAC survey provided essential information to adjust for hospital and team characteristics in the statistical models used in this study. Our research also departed from the prevailing approach to investigating NP service by taking measurement at the system rather than individual NP level. Implementation of the NP role in complex systems such as hospitals may have impacted on our findings given the multifaceted interactions between the NP role and the hospital system. ${ }^{32}$

A limitation of the study relates to the quality of ED performance data particularly when jurisdiction-level data are aggregated and reported at national level. All reported data showed differences in waiting times for all ATS categories but data custodians in some jurisdictions restricted our access to some of the data categories or declined to supply data despite HREC approval. Australian research has shown that ED performance data is subject to manipulation and fine-tuning ${ }^{33} 34$ which further compromises data integrity. Examination of the study findings raises questions about the strength of the causal link between NP service and the study outcomes. This, in part, can be attributed to inherent limitations of observational studies where there is minimal control over variables and consistency of intervention across multiple sites. Accordingly, reverse causation as discussed above could not be ruled out in this study design. Not-withstanding these limitations the findings and ensuing questions provide important foundation knowledge for formulation of hypotheses for subsequent experimental studies on the issues identified.

Overall, our study results show that on a systems level, prevailing NP staffing patterns have little or no effect on improvement of currently measured service indicators. The optimum number of emergency NPs relative to medical and nursing staffing, ED size and workload is unknown. If NPs are to be an effective ED workforce strategy, then further research to determine optimum ED skill mix and staffing ratio is warranted. Furthermore, an examination of the rationale for employing NPs in EDs may reveal variables that differentiate them from hospitals that do not employ NPs. Our results highlight the need for further consideration of the measurement of ED performance generally and in the context of team configuration, including the focus of NP service and the quality of service indicator data. Further research is also needed to examine the influence of NP care across all ED acuity levels on patient and service outcomes including staffing patterns in fast track service models.

At the time of our study, the majority of Australian NPs worked in EDs. Importantly, the NP role and scope of practice have since diversified with the validation of other NP specialty areas aside from the ED. ${ }^{35}$ Our findings therefore represent a measure of one model of NPs and should not be generalised to all NPs.

\section{CONCLUSION}

This study is innovative in its examination of ED NP service at a national level and has revealed new knowledge about 
Australian ED services. While this research has provided statistically reliable results relating to the influence of ED team configuration with and without NPs, these findings should be treated with caution. NPs are a relatively new inclusion into the ED workforce, and their numbers and roles are still being defined; our result may in part reflect the lack of critical mass of NP numbers per ED. Prevailing ED staffing models that include NPs have scant influence on the traditional service indicator metrics studied in this research raising questions about the need for more honed measures to evaluate ED NP service. Further research is needed to explain the dichotomy between the benefits identified in individual clinical outcomes NP research ${ }^{36}$ and these macro system-wide observations.

\section{Author affiliations}

${ }^{1}$ Nursing Research Institute, Australian Catholic University and St Vincent's Health Australia (Sydney), Darlinghurst, New South Wales, Australia

${ }^{2}$ School of Nursing, Institute of Health and Biomedical Innovation, Queensland University of Technology, Kelvin Grove, Queensland, Australia

${ }^{3}$ School of Public Health and Social Work, Queensland University of Technology, Kelvin Grove, Queensland, Australia

${ }^{4}$ School of Nursing and Midwifery, Deakin University, Geelong, Victoria, Australia ${ }^{5}$ Emergency Department, Lyell McEwin Hospital, Elizabeth Vale, South Australia, Australia

${ }^{6}$ School of Nursing and Midwifery, Curtin University, Perth, Western Australia, Australia

${ }^{7}$ National Centre for Epidemiology and Population Health (NCEPH), Australian National University, Canberra, Australian Capital Territory, Australia

${ }^{8}$ School of Medicine and Public Health, The University of Newcastle, Newcastle, Australia

Acknowledgements The authors gratefully acknowledge and thank all hospitals that participated in the study. The authors also thank Debra Berry, Huaqiong Zhou, Rosemary Phillips, Larissa Collins and Majella McCarthy for assistance with the preparation of ethics applications. We would also like to acknowledge valued support from our industry partners: the Office of the Chief Nursing and Midwifery Officer, Queensland Health; Clinician Planning and Leadership Unit, Queensland Health; Nursing and Midwifery Office, SA Health; Nursing and Midwifery Office, NSW Health; Chief Nurse and Midwifery Officer, Department of Health and Human Services, Victoria; Nursing and Midwifery Office, Department of Health, Western Australia. We would also like to acknowledge the funding sources listed below from the ARC and our industry partners.

Contributors GG, AG, SM, JC, GF, PD and LC conceived and developed the project and obtained funding. $A D$ liaised with data custodians, amassed and ordered the large databases. CDE conducted analysis of the data. GG, SM, AG, AD and OF wrote the first draft of the manuscript. All the authors made substantial contributions to interpretation of data and carried out a critical revision of the manuscript for important intellectual content. All the authors have seen and approved the final version of the manuscript.

Funding This study was funded by the Australian Research Council (LP140100320) and industry partners (Office of the Chief Nursing and Midwifery Officer, Queensland Health; Clinician Planning and Leadership Unit, Queensland Health; Nursing and Midwifery Office, SA Health; Nursing and Midwifery Office, NSW Health; Chief Nurse and Midwifery Officer, Department of Health and Human Services, Victoria; Nursing and Midwifery Office, Department of Health, Western Australia).

Competing interests None declared.

Patient consent for publication Not required.

Ethics approval The study was approved by Human Research Ethics Committees from participating universities and state health authorities for health facility approval included 13 full submissions to ethics committees. Approval was also obtained through administrative review (1), low and negligible risk applications (7), and site-specific governance applications (25).

Provenance and peer review Not commissioned; externally peer reviewed.
Data availability statement Data may be obtained from a third party and are not publicly available.

Open access This is an open access article distributed in accordance with the Creative Commons Attribution Non Commercial (CC BY-NC 4.0) license, which permits others to distribute, remix, adapt, build upon this work non-commercially, and license their derivative works on different terms, provided the original work is properly cited, appropriate credit is given, any changes made indicated, and the use is non-commercial. See: http://creativecommons.org/licenses/by-nc/4.0/.

\section{REFERENCES}

1. Tucker A, Bernard M. Making the case for nurse practitioners in the emergency department. Adv Emerg Nurs J 2015;37:308-12.

2. Forero R, McCarthy S, Hillman K. Access block and emergency department overcrowding. Crit Care 2011;15.

3. Australian Institute of Health and Welfare. Australian hospital statistics 2011-12: emergency department care. Health services series no. 45. Cat. no. HSE 126. Canberra: Australian Institute of Health and Welfare, 2012.

4. Australian Institute of Health and Welfare. Emergency department care 2016-17: Australian hospital statistics. Health services series no. 80. Cat. no. HSE 194. Canberra: Australian Institute of Health and Welfare, 2017.

5. Bernstein SL, Aronsky D, Duseja R, et al. The effect of emergency department crowding on clinically oriented outcomes. Acad Emerg Med 2009;16:1-10.

6. Di Somma S, Paladino L, Vaughan L, et al. Overcrowding in emergency department: an international issue. Intern Emerg Med 2015;10:171-5.

7. Sprivulis PC, Da Silva J-A, Jacobs IG, et al. The association between hospital overcrowding and mortality among patients admitted via Western Australian emergency departments. Med J Aust 2006;184:208-12.

8. Lowe G, Plummer V, O'Brien AP, et al. Time to clarify - the value of advanced practice nursing roles in health care. $J$ Adv Nurs 2012;68:677-85.

9. Doetzel CM, Rankin JA, Then KL. Nurse practitioners in the emergency department: barriers and facilitators for role implementation. Adv Emerg Nurs J 2016;38:43-55.

10. Jennings N, Clifford S, Fox AR, et al. The impact of nurse practitioner services on cost, quality of care, satisfaction and waiting times in the emergency department: a systematic review. Int J Nurs Stud 2015;52:421-35.

11. Currie J, Edwards L, Colligan M, et al. A time for international standards?: comparing the emergency nurse practitioner role in the UK, Australia and New Zealand. Accid Emerg Nurs 2007;15:210-6.

12. Gardner A, Della PR, Middleton S, et al. The status of Australian nurse practitioners: the first national census. Aust Health Rev 2009;33:679-89.

13. Middleton S, Gardner A, Gardner G, et al. The status of Australian nurse practitioners: the second National census. Aust Health Rev 2011;35:448-54.

14. Lowe G. Scope of emergency nurse practitioner practice: where to beyond clinical practice guidelines? Aust J Adv Nurs 2010;28:74-82.

15. leraci S, Digiusto E, Sonntag P, et al. Streaming by case complexity: evaluation of a model for emergency department fast track. Emerg Med Australas 2008;20:241-9.

16. Dinh M, Walker A, Parameswaran A, et al. Evaluating the quality of care delivered by an emergency department fast track unit with both nurse practitioners and doctors. Australas Emerg Nurs J 2012;15:188-94.

17. Carter AJE, Chochinov AH. A systematic review of the impact of nurse practitioners on cost, quality of care, satisfaction and wait times in the emergency department. CJEM 2007;9:286-95.

18. Rogers T, Ross N, Spooner D. Evaluation of a 'see and treat' pilot study introduced to an emergency department. Accid Emerg Nurs 2004;12:24-7.

19. Roche TE, Gardner G, Jack L. The effectiveness of emergency nurse practitioner service in the management of patients presenting to rural hospitals with chest pain: a multisite prospective longitudinal nested cohort study. BMC Health Serv Res 2017;17:445.

20. Dimeo M, Postic M. Lessons learned in developing and implementing the nurse practitioner role in an urban Canadian emergency department. J Emerg Nurs 2012;38:484-7.

21. Gardner G, Gardner A, Middleton S, et al. Mapping workforce configuration and operational models in Australian emergency departments: a national survey. Aust Health Rev 2017. 
22. Wilson A, Zwart E, Everett I, et al. The clinical effectiveness of nurse practitioners' management of minor injuries in an adult emergency department. Int J Evid Based Healthc 2009;7:3-14.

23. FitzGerald G, Jelinek GA, Scott D, et al. Republished paper: emergency department triage revisited. Postgrad Med J 2010;86:502-8.

24. Nursing and Midwifery Board of Australia. Guidelines on endorsement as a nurse practitioner, 2016. Available: https://www. nursingmidwiferyboard.gov.au/registration-and-endorsement/ endorsements-notations.aspx [Accessed 21 Jan 2019].

25. National Centre for Classification in Health. The International statistical classification of diseases and related health problems, 10th revision, Australian modification (ICD-10-AM) - Tabular list of diseases. 2nd edn. Sydney: National Centre for Classification in Health, 2000.

26. Considine J, Martin R, Smit D, et al. Emergency nurse practitioner care and emergency department patient flow: case-control study. Emerg Med Australas 2006;18:385-90.

27. Jennings N, O'Reilly G, Lee G, et al. Evaluating outcomes of the emergency nurse practitioner role in a major urban emergency department, Melbourne, Australia. J Clin Nurs 2008;17:1044-50.

28. Wilson A, Shifaza F. An evaluation of the effectiveness and acceptability of nurse practitioners in an adult emergency department. Int J Nurs Pract 2008;14:149-56.
29. Jennings N, Gardner G, O'Reilly G, et al. Emergency np model of care in an Australian emergency department. $J$ Nurse Pract 2015;11:774-81.

30. Jennings N, Gardner G, O'Reilly G, et al. Evaluating emergency nurse practitioner service effectiveness on achieving timely analgesia: a pragmatic randomized controlled trial. Acad Emerg Med 2015;22:676-84.

31. Hoot NR, Aronsky D. Systematic review of emergency department crowding: causes, effects, and solutions. Ann Emerg Med 2008:52:126-36.

32. Shiell A, Hawe P, Gold L. Complex interventions or complex systems? implications for health economic evaluation. BMJ 2008;336:1281-3.

33. Greene J, Hall J. The comparability of emergency department waiting time performance data. Med J Aust 2012;197:345-8.

34. Nocera A. Performance-based hospital funding: a reform tool or an incentive for fraud? Med J Aust 2010;192:222-4.

35. Helms C, Gardner A, McInnes E. Consensus on an Australian nurse practitioner specialty framework using Delphi methodology: results from the CLLEVER 2 study. J Adv Nurs 2017;73:433-47.

36. DesRoches CM, Clarke S, Perloff J, et al. The quality of primary care provided by nurse practitioners to vulnerable Medicare beneficiaries. Nurs Outlook 2017;65:679-88. 